\title{
0 crowdfunding como financiamento do jornalismo de investigação em Portugal
}

\author{
Ana Maria Fonseca ${ }^{1}$ \\ Henrique Morais Diz² \\ Maria José Palma Lampreia Dos-Santos ${ }^{3}$
}

Recibido: 2015-09-09

Enviado a pares: 2015-09-09
Aprobado por pares: 2015-10-29

Aceptado: 2016-04-08

DOI: $10.5294 /$ pacla.2016.19.3.9

Para citar este artículo / to reference this article / para citar este artigo

Fonseca A. M., Diz H. M. y Dos-Santos M. J. P. L. (2016). 0 crowdfunding como financiamento do jornalismo de investigação em Portugal. Palabra Clave 19(3), 893-918. DOI: 10.5294/pacla.2016.19.3.9

\section{Resumo}

O presente artigo analisa o crowdfunding aplicado ao jornalismo de investigação como alternativa aos modelos tradicionais de financiamento jornalístico em Portugal. O principal objetivo é inferir sobre as potencialidades de desenvolvimento do crowdfunding como financiamento do jornalismo de investigação português. Para esse efeito, com base em investigação empírica, contextualiza-se o crowdfunding, analisam-se as causas e as consequências do decréscimo acentuado do jornalismo de investigação português, bem como os seus impactos, e analisa-se, com base na metodologia estudo de caso, uma plataforma portuguesa dedicada a acolher projetos jornalísticos. Como principais resultados, salientam-se a ainda incipiente capacidade empreendedora dos jornalistas em Portugal e a necessidade futura dos seus programas curriculares no ensino superior em Portugal incluírem unida-

\footnotetext{
Universidade Losófona do Porto, Portugal. fonseca.anamaria@gmail.com

Universidade Losófona do Porto, Portugal. diz.henrique@gmail.com

DINAMIA'CET ISCTE-IUL and ESCS, Portugal.mjpls1963@gmail.com
} 
des curriculares de economia e de empreendedorismo na sua formação académica ao nível de licenciatura mestrado e doutoramento, de forma a aumentar o potencial empreendedor do jornalista nos tempos atuais e de se desenvolver o jornalismo de investigação.

\section{Palavras-chave}

Jornalismo de investigação; ensino superior; empreendedorismo; ciências da comunicação (Fonte: Tesauro da Unesco). 


\section{El crowdfunding como financiación del periodismo de investigación en Portugal}

\section{Resumen}

El presente artículo analiza el crowdfunding aplicado al periodismo de investigación como alternativa a los modelos tradicionales de financiación periodística en Portugal. El principal objetivo es inferir acerca de las potencialidades de desarrollo del crowdfunding como financiación del periodismo de investigación portugués. Para ello, con base en investigación empírica, se contextualiza el crowdfunding, se analizan las causas y las consecuencias del descenso pronunciado del periodismo de investigación portugués, así como sus impactos, y se analiza, basándose en la metodología estudio de caso, una plataforma portuguesa dedicada a recibir proyectos periodísticos. Como principales resultados, se destacan la aún incipiente capacidad emprendedora de los periodistas en Portugal y la necesidad futura de que sus programas curriculares en la educación superior en este país incluyan unidades curriculares de economía y de emprendimiento en su formación académica en el nivel de licenciatura, maestría y doctorado, a fin de aumentar el potencial emprendedor del periodista en la actualidad y de desarrollar el periodismo de investigación.

\section{Palabras Clave}

Periodismo de investigación; educación superior; emprendimiento; ciencias de la comunicación (Fuente: Tesauro de la Unesco). 


\section{Crowdfunding as a Way to Finance Investigative Journalism in Portugal}

\section{Abstract}

The article offers an analysis of crowdfunding applied to investigative journalism as an alternative to traditional models for funding journalism in Portugal. The primary objective is to understand and suggest the potential to develop crowdfunding for that purpose. Based on empirical research, crowdfunding is contextualized, the causes and consequences of the pronounced decline in Portuguese investigative journalism and the impact this has are analyzed, and the possibility of a Portuguese platform dedicated to receive journalistic projects is examined using the case study method. Essentially, the results highlight the still nascent entrepreneurial capacity of journalists in Portugal and the need for future curricula for higher education in Portugal to include subjects on economics and entrepreneurship as part of academic training for journalists at the undergraduate, master's and doctorate levels, so as to increase the entrepreneurial potential of today's journalists and to advance investigative journalism.

\section{Keywords}

Investigative journalism; higher education; entrepreneurship; communication sciences (Source: Unesco Thesaurus). 


\section{Introdução}

A crise económica e financeira do subprime, iniciada nos Estados Unidos da América em 2007, teve reflexos nas economias europeias em geral e na portuguesa em particular. Nesta última, conduziu, no caso do jornalismo, a uma redução de custos nas redações dos jornais. Um menor número de jornalistas passou a ser responsável por um maior número e uma maior diversidade de notícias.

Paralelamente, os cortes no financiamento à investigação jornalística, o incremento do "jornalismo de agência" e a indefinição sobre os modelos de financiamento dos jornais tradicionais e on-line conduziram a uma diminuição acentuada da qualidade e, principalmente, da quantidade de jornalismo de investigação.

Portugal fez, principalmente, desde o início da década de 2000, crescentes esforços na educação e na formação da sua população estudantil. Assim, os níveis de educação e de formação da população portuguesa têm sido progressivos. Dessa forma, assume-se que estamos perante cidadãos mais informados e recetivos à informação em geral, e ao jornalismo de investigação em particular. Essa situação per se faz surgir a necessidade de um novo paradigma no que respeita aos modelos de financiamento e à produção de notícias, como forma de contribuir para uma população mais informada e mais capacitada, na persecução de um dos objetivos do jornalismo, que é garantir a investigação e o subsequente acesso do público a temas específicos do seu interesse e não meramente submetidos à agenda dos media.

Simultaneamente, a indústria dos media vive uma das mais importantes crises da sua história recente, que não é alheia à crise económica e financeira global e à crescente oferta de notícias on-line, que a todo o momento desafiam os modelos de organização tradicionais dos media. Paralelamente, os padrões de consumo de notícias mudaram drasticamente nos últimos anos, com a imprensa e a televisão a registarem cada vez menos procura, ao mesmo tempo que disparou o consumo de notícias on-line (Becker, Gambaro e Souza Filho, 2015). 
O modelo tradicional dos jornais está assente num ambiente específico que já não existe (Carvajal, Garcia-Avilés e González, 2012). A isso há a acrescentar o incremento de aplicações para ler notícias em plataformas móveis, que vieram aumentar ainda mais a concorrência e acelerar estratégias de sobrevivência. As notícias tornaram-se um bem de consumo a custo zero. Qualquer utilizador pode, on-line, aceder a conteúdos gratuitamente com custos de produção menores (Carvajal et al., 2012), o que também ajuda a que hoje os editores lutem por encontrar um modelo de negócio sustentável que financie os seus jornais e a força de trabalho de que estes necessitam. Simultaneamente, as receitas provenientes da publicidade on-line são insuficientes para compensar as cada vez menores receitas da imprensa, pelo que se torna essencial reduzir custos. Dessa forma, restam muito poucos fundos que permitam financiar jornalismo de investigação de qualidade. A falta de recursos tem consequências nas redações: afeta a qualidade da investigação e da verificação de factos. Menos jornalistas a efetuarem mais notícias leva a um prejuízo da qualidade destas, a uma utilização excessiva de notícias provenientes de agências e a uma menor presença de correspondentes (Becker et al., 2015).

Assim, ao mesmo tempo que as redações cedem cada vez menos interesse e espaço ao jornalismo de investigação, os jornalistas freelancers têm cada vez menos oportunidades de trabalhar no jornalismo de investigação e de financiar os seus projetos. O crowdfunding (financiamento colaborativo) revela-se uma opção para esses profissionais. Paralelamente, os utilizadores podem sugerir tópicos do seu interesse, que acreditam merecerem atenção jornalística e investigação, e esse processo pode solucionar a uma importante lacuna no jornalismo atual (Carvajal et al., 2012). Por outro lado, uma das funções do jornalismo é a de dar voz a quem não a tem. Controlar o poder e dar voz a quem não a tem faz parte do processo jornalístico, principalmente, através da reportagem de investigação. O problema encontrase na indefinição perante os cortes mais intensos nas redações, nos custos com deslocações de jornalistas e nos correspondentes internacionais. Este é um papel necessário e indispensável à sociedade, e é nesse sentido que o crowdfunding aplicado a projetos jornalísticos pode fazer a diferença. Por um lado, há jornalistas que reúnem as condições necessárias para desenvol- 
ver os projetos de investigação jornalística, excluindo as restrições financeiras. Por outro, há público interessado em ver investigados assuntos que não têm espaço nos media tradicionais e dispostos a pagar por essa informação. À partida, estão reunidas todas as condições para que uma plataforma de crowdfunding aplicada ao jornalismo seja um sucesso no caso português.

O presente artigo tem como principais objetivos analisar um novo modelo de financiamento alternativo para o caso do jornalismo de investigação português que já é utilizado largamente noutros países, o crowdfunding, de forma a inferir as suas potencialidades no financiamento do jornalismo de investigação. Para esse efeito, contextualiza-se o crowdfunding em geral e aplicado ao jornalismo em particular, analisam-se os seus antecedentes, bem como outras formas alternativas de financiamento do jornalismo de investigação e as motivações intrínsecas ao crowdfunding; finalmente, estuda-se o estudo de caso de uma plataforma portuguesa dedicada a acolher projetos jornalísticos, de forma a entender as futuras potencialidades de desenvolvimento e a forma de ultrapassar as suas limitações, no que diz respeito aos aspetos curriculares dos cursos de jornalismo atuais.

\section{Antecedentes e desenvolvimento do crowdfunding}

A economia da partilha ou o financiamento colaborativo, no caso do jornalismo, teve origem na Spot.us, que é uma plataforma baseada na comunidade para jornalistas na Califórnia, criada em 2006 por David Cohn (Carvajal et al., 2012). No entanto, a origem do termo crowdfunding resulta da sua adaptação a outro conceito que, durante algum tempo, se anunciou como precursor da morte do jornalismo, o crowdsourcing. Nesse âmbito, acreditouse que cada utilizador podia ser um jornalista, numa ideia que também ficou conhecida como jornalismo do cidadão e de que hoje restam apenas alguns parcos exemplos colaborativos e não substitutivos.

Howe (2007) utilizou pela primeira vez o termo crowdsourcing para definir o processo pelo qual uma rede obtém recursos como ideias, soluções ou contribuições relacionadas com atividades económicas. $\mathrm{O}$ crowdfunding 
ocorre quando uma empresa orientada para o lucro terceiriza tarefas específicas essenciais para a produção ou a venda do seu produto para o público em geral, sob forma de apelo (open call) na internet, com a intenção de motivar os indivíduos a fazerem uma contribuição voluntária para o processo produtivo da empresa de forma gratuita ou significativamente menor daquela que os contribuidores representam para a empresa (Kleemann, Vob e Rieder, 2008). As empresas criam valor utilizando os consumidores como voluntários e força de trabalho quase gratuita. Estes últimos autores, bem como Lawton e Marom (2010), e Carvajal et al. (2012), identificam a Web 2.0 como um pré-requisito para o desenvolvimento do crowdsoursing. A partir do conceito de crowdsoursing, chegou-se à conclusão de que é possível usufruir do poder de cativar o público para financiar pequenos projetos que dificilmente seriam financiados pelos meios tradicionais, recorrendo às redes sociais como o Twitter e o Facebook (Gerber, Hui e Kuo, 2012), dando assim origem ao conceito de crowdfunding.

O crowdfunding define-se como o processo relacionado com financiamento por meio do qual projetos ou empresas usam a rede web para solicitar e receber fundos da multidão sob a forma de donativos monetários, às vezes em troca de um futuro produto, serviço ou recompensa (Kleemann et al., 2008; Belleflamme, Lambert e Schwienbacher, 2014). A internet e as redes sociais estão, pela sua natureza, no centro desses conceitos porque todo o processo é aí efetuado. No seu âmbito mais generalista, o crowdfunding tem como objetivo cativar o público para financiar pequenos projetos que dificilmente seriam financiados por sistemas financeiros tradicionais, recorrendo nesse caso às redes sociais como o Twitter, $\mathrm{o}$ Facebook etc. (Gerber et al., 2012). Há pouco mais de uma década, apareceram as primeiras plataformas de crowdfunding como ferramenta de comunidade e distribuição, estando o seu desenvolvimento diretamente relacionado ao progresso da web e das aplicações e serviços da rede móvel. Empreendedores e empresas podem utilizar a multidão para obter ideias, angariar dinheiro, além de solicitar opiniões sobre o produto, criando um ambiente de apoio global e de tomada de decisões coletivas, permitindo aos negócios ligarem-se com potenciais clientes (De Buysere, Gajda, Klevelan e Marom, 2012). 
Contudo, já em 1997, surgiu o percursor do crowdfunding quando os fãs norte-americanos da banda Marillion contribuíram on-line com 60 mil dólares que lhes permitiu partir em turnê. Em 2003, surgiu a ArtistShare, que foi a primeira plataforma de crowdfunding generalista na internet. Outro percursor do crowdfunding foi Perry Chan, quando, em 2002, pretendeu organizar uma festa, mas não tinha o orçamento necessário para contratar artistas. Mais tarde, apercebeu-se que se tivesse conseguido cativar o interesse dos possíveis convidados, talvez tivesse sido possível financiar todo o evento, angariando doações antes da festa. A ideia foi evoluindo ao longo dos anos, até 2009, ano em que conseguiu lançar o KickStarter.com. Foi com o seu advento inicial que, em 2009, o financiamento coletivo por meio da internet ganhou maior visibilidade (Bogost, 2012).

A simplicidade do crowdfunding é um dos segredos do sucesso dessa plataforma, bem como as regras estabelecidas para o funcionamento do processo de financiamento. Todos os projetos presentes na plataforma têm de estar inseridos nas artes criativas, não podem ser iniciativas de solidariedade, têm de declarar o montante que o projeto necessita de alcançar e a respetiva data de término. Caso os projetos não alcancem o montante previsto no período de tempo estipulado, todas as doações são devolvidas aos financiadores (Steinberg, De Maria e Migicovsky, 2012).

A partir daí, várias plataformas de crowdfunding internacionais surgiram e expandiram-se em diferentes áreas e domínios, como a IndieGoGo e o RocketHub, que são também utilizadas para financiar projetos generalistas semelhantes. Contudo, estas últimas optaram por um modelo de financiamento diferente, em que o criador pode conseguir financiar um projeto ainda que não alcance a meta estipulada. Para esse propósito, as plataformas de crowdfunding proporcionam um espaço de encontro entre criadores e financiadores para trocar recursos de modo a dar corpo às ideias (Howe, 2008; Belleflamme et al., 2014; Belleflamme, Lambert e Schwienbacher, 2010; Steinberg et al., 2012). As plataformas on-line recebem, assim, candidaturas de criadores que pretendem expor o seu negócio, ideia ou causa. Algumas plataformas fazem uma pré-seleção das ideias baseadas nos seus próprios critérios, enquanto outras publicam automaticamente todos os 
projetos. No primeiro caso, a seleção baseia-se normalmente na experiência do promotor do projeto e na sua exequibilidade. Depois de a ideia ser aceite na plataforma, a tarefa do criador é fazer uma apresentação para um determinado período de tempo e um objetivo financeiro, de modo a cativar potenciais financiadores. Seguidamente, os financiadores apoiam a ideia, por meio de donativos financeiros, diretamente pela plataforma de crowdfunding. Durante a campanha de angariação, o criador mantém atualizações sobre o estado do projeto na mesma plataforma. Após o investimento inicial, muitos financiadores optam por continuar envolvidos no processo de decisão e estratégia geral do projeto e, em muitos casos, a comunicação entre ambas as partes continua, no decorrer do projeto, pela plataforma on-line (Agrawal, Catalini e Goldfarb, 2011; 2013; Mollick, 2014).

No que diz respeito a projetos jornalísticos, a Spot.us é a primeira e a mais conceituada plataforma internacional. Esse site tem operado como uma comunidade que financia freelancers e jornalistas por meio de donativos dos utilizadores. Os jornalistas apresentam o seu trabalho aos utilizadores ou são estes mesmos que indicam um tema sobre o qual gostariam de obter investigação jornalística. Enquanto os jornalistas esperam obter financiamento e o seu trabalho vai ganhando forma, os financiadores confiam na resposta daqueles. Se os primeiros forem bem-sucedidos, os meios tradicionais podem depois comprar as histórias em questão e publicá-las. Caso contrário, são apenas publicadas no site. Dessa forma, os jornalistas regressam ao seu papel original de intermediários. Essa relação decorre na plataforma, promovendo a transparência e tornando-se possível por meio dos donativos dos financiadores. (Belleflamme et al., 2014). Assim, o crowdfunding agrega o poder da multidão para financiar pequenos empreendimentos, projetos com poucas possibilidades de serem apoiados pelos meios tradicionais.

\section{As motivações para participação e financiamento do crowdfunding}

De acordo com Kleemann et al. (2008), os participantes nos projetos de crowdsourcing, percursor do crowdfunding, têm motivações intrínsecas e extrínsecas. No primeiro caso, agem movidos pelo prazer ou pelo divertimento de executar determinada tarefa, enquanto as motivações extrínsecas se re- 
lacionam com uma recompensa externa, como dinheiro, bens, benefícios profissionais, aprendizagem, reconhecimento ou até um certo grau de insatisfação com produtos correntes.

Gerber et al. (2012) e Agrawal et al. (2013) concluem que, no caso do crowdfunding, os indivíduos são motivados a participar pelas interações sociais proporcionadas pelas plataformas, pelo desejo de desenvolvimento de uma ideia e pelas múltiplas interações e feedback entre participantes e criadores. Para estes, existem ainda motivações financeiras devido aos baixos custos de investimento necessário, bem como o acesso facilitado a muita informação. No caso dos financiadores, desenvolvem-se sentimentos de ligação a uma comunidade com interesses e ideias semelhantes. Os incentivos dos financiadores passam ainda por três aspetos distintos: 0 acesso a oportunidades de investimento, a participação na comunidade e o apoio a um produto, serviço ou ideia. A filantropia desempenha também um papel importante na maioria das plataformas de crowdfunding e na formalização de contratos (Agrawal et al., 2013). Aitamurto (2011) conclui que a motivação principal dos financiadores é contribuir para o bem comum e a mudança social. Dessa forma, eles são também promotores do jornalismo de investigação.

No que respeita aos incentivos das plataformas, tratando-se usualmente de negócios com propósitos lucrativos, o seu objetivo é maximizar a quantidade e a dimensão dos projetos bem-sucedidos. Isso requer atrair uma extensa comunidade de financiadores, bem como conceber o mercado para atrair projetos de alta qualidade, reduzir a fraude e facilitar um encontro eficiente entre ideias e capital. As plataformas de crowdfunding também têm por finalidade atrair projetos que possam provocar grande atenção dos media, porque dessa forma podem expandir a comunidade já existente de financiadores, permitindo à plataforma expandir-se em direção a novas categorias (Agrawal et al., 2013).

Algumas desvantagens nesse modelo são o risco dos criadores transmitirem demasiada informação sobre as suas ideias de produtos ou serviços, bem como, do lado dos financiadores, a possibilidade de fraude, a 
incompetência do criador ou o risco do próprio projeto. Esses problemas podem, segundo Agrawal et al. (2013), gerar uma falha nesse mercado, que pode ocorrer por uma variedade de causas resultantes da relação menos transparente entre criadores e financiadores, ou mesmo de uma má avaliação por parte destes últimos.

Segundo De Buysere et al. (2012), as motivações que levam os utilizadores a financiarem determinados projetos incluem o retorno social, material ou financeiro. No primeiro caso, os financiadores ficam satisfeitos ao saberem que o projeto pode ser realizado, constituindo esta uma motivação intrínseca, que ocorre principalmente nos projetos que se baseiam em donativos e por organizações com fins não lucrativos. No caso do retorno financeiro, o financiador pode simular uma pesquisa de marketing por meio do feedback dado pelos utilizadores.

Aitamurto (2011) definiu a plataforma jornalística Spot.us como um caso de utilização de inteligência coletiva ao serviço do jornalismo. Defende que o processo jornalístico por meio de crowdfunding cria um laço forte entre os jornalistas e os financiadores e muda também a relação dos jornalistas com as audiências. Os utilizadores e os leitores estão ansiosos de informação que satisfaça a sua curiosidade ou em ajudar na tomada de decisões sobre a sua vida. Os financiadores desses projetos de crowdfunding tornam-se assim gate keepers nesse ecossistema.

\section{O financiamento do crowdfunding}

$\mathrm{O}$ crowdfunding capta verbas para investir, geralmente, utilizando as redes sociais. Em vez de angariar financiamento por meio do sistema financeiro tradicional, o crowdfunding ajuda indivíduos ou empresas a obterem financiamento por meio de uma grande audiência, a multidão, na qual cada indivíduo providencia uma pequena quantia. Do ponto de vista financeiro, pode ser definido como a cooperação coletiva de indivíduos que aplicam o seu dinheiro num projeto ou produto. De um ponto de vista económico, proporciona um melhor ajustamento entre a oferta e a procura, que resulta num processo de produção mais eficiente (Belleflamme et al., 2014). 
Na perspetiva financeira dos indivíduos que lançam e financiam projetos nas plataformas, os criadores tentam gerar valor para os que os apoiam, segundo os fundadores das maiores plataformas. Embora não se trate de uma doação, o crowdfunding também não é um investimento. A relação entre criadores e financiadores é nova e está profundamente relacionada com as economias das redes sociais. Os financiadores obtêm sempre algo em troca dos projetos que apoiam, mas os financiadores não são investidores, na medida em que geralmente não obtêm benefícios financeiros, nem são acionistas (Barabas, 2012).

Em comparação com o apoio de serviços financeiros, uma diferença basilar reside no financiador que participa no crowdfunding que habitualmente possui um aspeto de empreendedor associado ao seu entusiasmo, compreendendo o potencial do projeto e tendo a necessidade intrínseca de se tornar uma parte do grupo que vai "fazer acontecer". Frequentemente, o financiador não possui recursos suficientes para financiar um projeto por inteiro ou o mesmo leque de competências que pode ser encontrado num especialista de uma sociedade de capital de risco. No entanto, o financiador identificase habitualmente com o projeto, está aberto à mudança e fica satisfeito por ajudar a dar um cunho social ao projeto (De Buysere et al., 2012).

Schwienbacher e Larralde (2010) defendem que uma multidão pode muitas vezes ser mais eficiente do que um indivíduo isolado ou mesmo uma equipa, na resolução de determinados problemas empresariais. Segundo esses autores, o risco assumido por cada investidor é também menor, não apenas porque cada um contribui individualmente com um valor mais reduzido, mas também porque a multidão contribuidora torna-se potencial consumidora do produto ou serviço em questão, além de ter um incentivo extra para o divulgar, uma vez chegado ao mercado.

Até agora, a maximização do lucro tem sido um objetivo raro no crowdfunding. Ao mesmo tempo, o risco de falhar não se traduz necessariamente em risco de perda de capital, porque o sucesso, para o financiador, não se define normalmente por meio do retorno financeiro (De Buysere et al., 2012). Estes autores, conjuntamente com Agrawal et al. (2011; 2013), Mollick (2014) e Rivera (2012), propõem uma classificação exaustiva de doze 
modelos distintos de financiamento de crowdfunding, revelando uma variedade de opções cujo potencial aumenta quanto mais forem combinadas entre si: donativos, recompensas, pré-vendas, empréstimos, empréstimos sociais, empréstimos peer-to-peer (particulares), empréstimo peer-to-business, capital próprio, partilha de lucros, recompensa em género, financiamento em género, para além de donativos e de recompensas e dos modelos híbridos nos quais se combinam duas ou mais modalidades de financiamento anteriores. Nestes dois últimos modelos, a maior motivação dos financiadores é social, intrínseca, o que habitualmente é uma boa base para uma relação de longo termo. Os empréstimos são outra forma de financiamento do crowdfunding quando uma empresa pede dinheiro emprestado a um grupo de pessoas em vez de o fazer a uma instituição financeira (Ramos, González, Llorca, Mayor e Porcel, 2013).

O valor certo nem sempre está definido no início do projeto, estando sujeito a algum risco para os financiadores. De igual forma, também é possível participar num projeto de crowdfunding oferecendo produtos ou serviços em vez de pagamentos em numerário. Algumas plataformas arriscam uma combinação de empréstimo e pré-vendas. Uma percentagem do financiamento é colocado num empréstimo, enquanto outra parte é usada para pré-financiar a produção do produto ou serviço.

\section{0 desenvolvimento do crowdfunding em Portugal}

Em Portugal, as primeiras plataformas generalistas de crowdfunding surgiram em 2011, oferecendo um serviço semelhante ao da americana KickStarter. Atualmente, existem duas de âmbito generalista: Massivmov e o PPL, que acolhem propostas de diversas índoles, com um denominador comum, isto é, projetos empreendedores que visem à criação de valor para o empreendedor, para os apoiantes e para a sociedade em geral. Recentemente, foi publicado no Diário da República a Lei 102/2015, referente ao regime jurídico do crowdfunding ou financiamento colaborativo.

Os dados mais recentes publicados sobre crowdfunding para o caso português, em todas as plataformas, quer de projetos generalistas, quer jor- 
nalísticos apontam para transações de valores na ordem de 1,5 milhões de euros, desde que estas surgiram em Portugal. Embora esse valor seja ainda reduzido, sobretudo se comparado com o mercado norte-americano, a tendência é de crescimento. Esses valores são apenas uma estimativa, já que não existem dados de estatísticas oficiais, por isso baseia-se no somatório dos diferentes valores das plataformas existentes em Portugal. Na PPL, uma das mais conhecidas, a taxa de sucesso ronda os $49 \%$ e foram angariados até ao momento 1,2 milhões de euros com 919 projetos publicados ao longo dos últimos quatro anos.

A plataforma Massivemov angariou, desde 2011, um total de 103,5 mil euros, com uma taxa de sucesso de $52 \%$, tendo sido financiados 33 projetos. $\mathrm{O}$ valor médio de apoio situa-se nos 33 euros no caso da PPL e nos 46 euros na plataforma Massivemov.

No que diz respeito ao jornalismo, as plataformas de crowdfunding seguem um processo similar às generalistas, direcionadas para todo o tipo de projetos de âmbito artístico, para desenvolvimento de um produto ou obra, entre outros. Primeiro, os jornalistas lançam um projeto de investigação jornalística, documentário ou reportagem fotográfica. Os utilizadores da plataforma patrocinam o projeto e, quando o jornalista atinge o seu objetivo financeiro, pode utilizar o valor para trabalhar nele. Nesses casos, os financiadores são compensados ou pela gratidão simbólica de verem o trabalho publicado, ou por receberem uma recompensa do profissional.

\section{A plataforma portuguesa de jornalismo de investigação I Fund News}

No que diz respeito a plataformas exclusivas para projetos jornalísticos, atualmente existem apenas duas em Portugal: a I Fund News e a TKNT (Televisão que não é Televisão). Esta última produz uma edição semanal de uma televisão que pode ser considerada alternativa e que, no seu site, detalha os custos mensais da plataforma e as finalidades com que será usada cada uma das contribuições de cinco euros, valor que cada um dos utilizadores pode contribuir para o projeto a título individual. Ela foi excluída desta análise uma vez que se propõe levar a cabo uma emissão semanal de televisão, afastando-se, por isso, ao âmbito pretendido. 
Com a finalidade de estudar a plataforma I Fund News, utilizou-se a metodologia estudo de caso, na qual analisámos desde a sua criação, por meio de todas as fontes documentais existentes, dos media, e com base numa entrevista ao gestor de inovação da Plataforma (Carvalhão, comunicação pessoal, 2015), além de entrevistas informais a jornalistas e especialistas sobre todo o processo. Perante os condicionalismos e as restrições financeiras associadas a uma população com níveis habilitacionais superiores em Portugal, além de existir um grande número de profissionais de jornalismo, seria expectável que uma plataforma de crowdfunding, criada para acolher exclusivamente projetos jornalísticos, teria grande procura por parte dos profissionais de jornalismo e do público em geral. Mas, na verdade, isso não aconteceu. Lançada em novembro de 2013, a plataforma I Fund News foi, desde logo e posteriormente, notícia em diversos meios de comunicação on-line e tradicionais, das revistas às televisões, das edições on-line aos jornais impressos, passando pelos blogues da especialidade. Além disso, foram contactados diversos jornalistas no ativo, de imprensa e televisão, e, por outro lado, contactadas todas as universidades do país com cursos de jornalismo, por meio de uma "turnê de divulgação", numa ação que visou "bater porta a porta para ir ter diretamente com as pessoas potencialmente interessadas". Foi ainda criada uma página de Facebook, atualmente em funcionamento. Durante cerca de seis meses, essa plataforma contou com uma equipa de duas pessoas alocadas ao projeto em permanência e diversos colaboradores na fase inicial da Edge Innovation, que é a empresa que gere a plataforma.

Não obstante, mais de um ano decorrido sobre o seu lançamento, apenas um projeto de investigação jornalística multiplataforma teve lugar e foi bem-sucedido utilizando essa plataforma, o "Até Lá Abaixo", que atingiu mais do que $100 \%$ do valor que se propôs angariar, sendo o único projeto proposto pelos jornalistas para investigação. Os responsáveis dessa plataforma indicaram que não havia interesse, nem dimensão suficiente de oferta por parte dos jornalistas, enquanto do lado dos financiadores houve uma boa resposta, atendendo a que o único projeto existente ultrapassou inclusive o seu financiamento global solicitado. A dimensão restrita da procura do mercado português por crowdfunding foi, aliás, reforçada em todas as entrevistas 
e as fontes documentais primárias e secundárias. Esses resultados indiciam que o sistema de ensino superior está a formar jornalistas com baixa capacidade empreendedora, bem como de internacionalização e cultura.

O modelo de funcionamento dessa plataforma é similar a outros sites em funcionamento em diversos países e inspirado na plataforma Spotus. com. Os jornalistas apresentam uma ideia para um artigo, os interessados contribuem com um mínimo de um euro e meio. O valor total do financiamento é definido pelo jornalista, mas um particular ou entidade não poderá contribuir com mais do que $20 \%$ do valor pedido, ficando a empresa gestora da plataforma, a Edge Innovation, com $15 \%$ do montante angariado.

Os objetivos da plataforma estão, conforme Carvalhão (2015), em consonância com os objetivos gerais das plataformas de jornalismo de investigação financiado por meio de crowdfunding, "pretendendo colmatar as falhas dos órgãos de comunicação existentes e dar um espaço de publicação a jornalistas independentes", além "de pretender servir de espaço de utilidade para jornalistas promissores que estão no desemprego". Para se inscrever na plataforma, o jornalista tem de possuir carteira profissional. Depois dessa verificação, o jornalista é livre de propor e aceitar financiamento para qualquer tema. Também o processo de publicação é inteiramente controlado por quem escreve. Após a publicação, os textos ficam dois ou três meses com acesso limitado, tornando-se, depois, de acesso livre.

O objetivo do projeto era, de acordo com os seus responsáveis (Carvalhão, 2015), "ter impacto social, encontrando soluções para jornalistas desempregados ou freelancers e até a possibilidade de estes poderem desenvolver um emprego mais informal”. Por outro lado, estava aberta a possibilidade de os jornalistas proporem projetos controversos que não tivessem lugar noutros meios tradicionais e que, por meio dessa plataforma, podiam ser investigados. $\mathrm{O}$ projeto inicial compreendia três fases, mas, por não ter havido continuidade, acabaram por ficar na fase beta, ou seja, na fase inicial. Apesar da fraca adesão, a plataforma I Fund News contínua disponível para utilização. 
Diversos autores, em particular Mollick (2014) e Agrawal et al. (2011; 2013), estudaram os casos de sucesso e insucesso dos projetos e os fatores determinantes que podem levar a um caso ou a outro. No entanto, nenhum deles pode ser especificamente aplicado ao caso do I Fund News, plataforma que falhou ainda antes de ter projetos suficientes para que se pudesse fazer uma aplicação desses modelos. Em Portugal, a maioria dos especialistas concorda que o mercado português é de reduzida dimensão.

No sentido de inferirmos sobre a vertente empreendedora dos jornalistas desde a sua formação inicial, analisámos os planos curriculares de todos os cursos de licenciatura e de mestrado em Ciências da Comunicação (CC) e Jornalismo e os doutoramentos na área de Ciências da Comunicação (por não existirem especificamente em jornalismo neste último grau), lecionados em todas as Instituições de Ensino Superior (IES) em Portugal (PT), públicas e privadas, apresentados na Tabela 1. Das seis licenciaturas existentes, apenas quatro delas, isto é, cerca de três quartos da amostra, possuem unidades curriculares (UC) da área de Economia, que em média perfazem apenas uma UC introdutória com cerca de $5 \mathrm{ECTS}^{4}$. No grau mestre, verifica-se a completa ausência, quer nas IES públicas e privadas, de UCs de Economia, Empreendedorismo, quer em qualquer outra UC dessas áreas científicas. Nos doutoramentos em $\mathrm{CC}$, a situação não é muito distinta dos mestrados. Assim, apenas numa Universidade Privada em PT, a Universidade Lusófona do Porto (ULP), existe a UC de Economia Social e do Desenvolvimento, que aborda, para além da componente de economia social, o desenvolvimento e os fatores que a condicionam, nomeadamente: a ordem internacional, o crescimento e a estagnação, a população, a saúde, a educação, o desenvolvimento económico e as transformações estruturais, o desenvolvimento tecnológico, industrial e agrícola, a política e a cultura. A UC possui 7,5 ECTS e a sua avaliação encontra-se dependente da realização pelos doutorandos de um artigo científico com peer review e indexação em bases de relevo. Nesse trabalho, os estudantes são incentivados a investigarem as causas e as problemáticas inerentes ao desenvolvimento setorial e à economia social aplicadas à comunicação para o desenvolvimento.

4 ECTS - European Credit Transfer System válido nos Países da União Europeia que aderiram ao "Processo de Bolonha”, que traduz o tempo de trabalho efetuado pelos estudantes em cada área científica e unidade curricular. 
Pontualmente, no doutoramento da Universidade Católica, existe uma opção de Economia da Cultura (Tabela 1), mas entre 26 opções possíveis de escolha, com pouca probabilidade de ser selecionada, principalmente, por se tratar de uma Faculdade de Ciências Humanas. A quase completa ausência de UCs da área de Economia/Gestão (incluindo-se nesta última o empreendedorismo) nos graus académicos lecionadas pelas IES, explicase, por um lado, porque em grande parte das IES esses mesmos graus são lecionados nas Faculdades de Letras ou similares, porque a perceção da importância do empreendedorismo e da economia ainda não é sentida entre os experts portugueses de CC, que estavam no passado associados a profissões com empregos por conta de outrem outrora assegurados, em que a capacidade empreendedora era baixa ou inexistente. Constatamos uma lacuna na formação superior de jornalistas em Portugal que, embora não dizendo respeito especificamente à componente científica do jornalista em geral, acaba por ser uma lacuna de uma soft skill muito importante face às dificuldades profissionais com que se debatem a maioria dos jornalistas atuais, não possuindo quer as ferramentas de análise económica, quer o dinamismo empreendedor capaz de criarem o seu autoemprego.

\section{Tabela 1. Análise da presença das áreas científicas de Economia/Gestão/Empreendedorismo nos Planos Curriculares das IES em Portugal}

\begin{tabular}{|c|c|c|c|}
\hline \multicolumn{4}{|c|}{ Grau de Licenciado - Ensino Superior Universitário Público } \\
\hline Universidade & Curso & $\begin{array}{l}\text { ECTS/ } \\
\text { n. de UC } \\
\text { Economia/ } \\
\text { Gestão }\end{array}$ & Unidades curriculares \\
\hline Universidade (U) de Coimbra & Jornalismo e Comunicação & n.a. & n.a. \\
\hline $\begin{array}{c}\text { U. do Porto - Faculdade de } \\
\text { Letras }\end{array}$ & $\begin{array}{c}\text { Ciências da Comunicação: } \\
\text { Jornalismo, Assessoria, } \\
\text { Multimédia }\end{array}$ & $\begin{array}{l}6 \\
6\end{array}$ & $\begin{array}{l}\text { Introdução à Economia } \\
\text { Economia dos Media }\end{array}$ \\
\hline $\begin{array}{c}\text { U. de Coimbra - Faculdade de } \\
\text { Letras }\end{array}$ & Jornalismo & 6 & $\begin{array}{l}\text { Socioeconomia dos Media } \\
\text { (área científica de Ciências } \\
\text { da Comunicação e não } \\
\text { ECO) }\end{array}$ \\
\hline \multicolumn{4}{|c|}{ Grau de Licenciado - Ensino Superior Universitário Privado } \\
\hline $\begin{array}{l}\text { U. Lusófona de Humanidades e } \\
\text { Tecnologias - Lisboa }\end{array}$ & Comunicação e Jornalismo & 4 & Jornalismo Económico \\
\hline
\end{tabular}




\begin{tabular}{|c|c|c|c|}
\hline \multicolumn{4}{|c|}{ Grau de Licenciado - Ensino Superior Público Politécnico } \\
\hline $\begin{array}{c}\text { Instituto Politécnico (IP) de } \\
\text { Lisboa - ESCS }\end{array}$ & Jornalismo & 5 & Análise Económica \\
\hline IP Portalegre - ESE & Jornalismo e Comunicação & n.a. & n.a. \\
\hline \multicolumn{4}{|c|}{ Grau de Mestre - Ensino Superior Universitário Público } \\
\hline U. Beira Interior & Jornalismo & n.a. & n.a. \\
\hline $\begin{array}{c}\text { U. de Coimbra - Faculdade de } \\
\text { Letras }\end{array}$ & Comunicação e Jornalismo & n.a. & n.a. \\
\hline U. Minho & $\begin{array}{l}\text { Ciências da Comunicação - } \\
\text { Informação e Jornalismo }\end{array}$ & n.a. & n.a. \\
\hline $\begin{array}{c}\text { Universidade Nova de Lisboa - } \\
\text { Faculdade de Ciências Sociais e } \\
\text { Humanas }\end{array}$ & Jornalismo & n.a. & n.a. \\
\hline \multicolumn{4}{|c|}{ Grau de Mestre - Ensino Superior Universitário Privado } \\
\hline $\begin{array}{c}\text { U. Lusófona de Humanidades e } \\
\text { Tecnologias }\end{array}$ & $\begin{array}{c}\text { Jornalismo, Política e História } \\
\text { Contemporânea }\end{array}$ & n.a. & n.a. \\
\hline U. Católica Portuguesa — Braga & $\begin{array}{c}\text { Comunicação Social: Média e } \\
\text { Jornalismo }\end{array}$ & n.a. & n.a. \\
\hline \multicolumn{4}{|c|}{ Grau de Mestre — Ensino Superior Público Politécnico } \\
\hline $\begin{array}{c}\text { Instituto Politécnico (IP) de } \\
\text { Lisboa - ESCS }\end{array}$ & Jornalismo & n.a. & n.a. \\
\hline IP Portalegre — ESE & $\begin{array}{c}\text { Jornalismo, Comunicação e } \\
\text { Cultura }\end{array}$ & n.a. & n.a. \\
\hline \multicolumn{4}{|c|}{ Grau de Doutor - Ensino Superior Público/Privado Universitário } \\
\hline $\begin{array}{c}\text { Universidade Católica Portuguesa } \\
\text { — Faculdade de Ciências } \\
\text { Humanas }\end{array}$ & Ciências da Comunicação & 6 - opcional & $\begin{array}{l}\text { Opção Economia da } \\
\text { Cultura (entre 26 UCs) }\end{array}$ \\
\hline $\begin{array}{l}\text { U. Lusófona de Humanidades e } \\
\text { Tecnologias }\end{array}$ & Ciências da Comunicação & n.a. & n.a. \\
\hline $\begin{array}{c}\text { ULHT - Universidade Lusófona } \\
\text { de Lisboa - Com o ISCTE - } \\
\text { IUL/UBI/U. Minho }\end{array}$ & $\begin{array}{c}\text { Estudos de Comunicação: } \\
\text { Tecnologia, Cultura e Sociedade }\end{array}$ & n.a. & n.a. \\
\hline Universidade Lusófona do Porto & $\begin{array}{c}\text { Estudos em Comunicação para o } \\
\text { Desenvolvimento }\end{array}$ & 7,5 & $\begin{array}{c}\text { Economia Social e do } \\
\text { Desenvolvimento }\end{array}$ \\
\hline $\begin{array}{c}\text { U. de Coimbra — Faculdade de } \\
\text { Letras }\end{array}$ & Ciências da Comunicação & $\begin{array}{l}\text { n.a. (opções } \\
\text { livres CSH) }\end{array}$ & $\begin{array}{l}\text { n.a. (não inclui curso } \\
\text { doutoral) }\end{array}$ \\
\hline $\begin{array}{c}\text { Universidade de Lisboa - } \\
\text { Faculdade de Letras }\end{array}$ & $\begin{array}{l}\text { Ciências da Cultura - } \\
\text { Comunicação e Cultura }\end{array}$ & n.a & n.a. (seminário optativo) \\
\hline $\begin{array}{c}\text { U. L. - Faculdade de Letras } \\
\text { (com a Faculdade de Medicina L.) }\end{array}$ & Voz, Linguagem e Comunicação & n.d. & n.d. \\
\hline $\begin{array}{c}\text { UTAD — Escola de Ciências } \\
\text { Humanas e Sociais }\end{array}$ & $\begin{array}{c}\text { Direção de Comunicação } \\
\text { Empresarial }\end{array}$ & n.a. & n.a. \\
\hline $\begin{array}{l}\text { U. do Algarve - Faculdade de } \\
\text { Ciências Humanas e Sociais }\end{array}$ & Comunicação, Cultura e Artes & n.a. & n.a. \\
\hline U. Minho & Ciências da Comunicação & n.a. & n.a. \\
\hline
\end{tabular}




\begin{tabular}{|c|c|c|c|}
\hline $\begin{array}{c}\text { U. do Porto - Faculdade de } \\
\text { Letras em associação com U. } \\
\text { Aveiro }\end{array}$ & $\begin{array}{l}\text { Informação e Comunicação em } \\
\text { Plataformas Digitais }\end{array}$ & n.a. & n.a. \\
\hline $\begin{array}{l}\text { U. Nova de Lisboa - Faculdade } \\
\text { de Ciências Sociais e Humanas }\end{array}$ & Ciências da Comunicação & n.a. & 1 opção livre (10 ECTS) \\
\hline ISCTE — IU Lisboa & Ciências da Comunicação & n.a. & n.a. \\
\hline $\begin{array}{l}\text { UBI - Universidade da Beira } \\
\text { Interior }\end{array}$ & Ciências da Comunicação & n.a. & n.a. \\
\hline
\end{tabular}

Legenda: n.a. — não admissível; n.d. - não se encontra informação disponível.

Fonte: Acesso Ensino Superior; A3ES e páginas das Instituições de Ensino Superior, 2015.

Os resultados obtidos são ainda confirmados por Roncallo-Dow, Uribe-Jongbloed e Calderón- Reyes (2013). Segundo esses autores, um dos pontos-chave está relacionado com a necessidade de formar profissionais em comunicação dotados de pensamento crítico, que lhes permita compreender a realidade que eles terão de enfrentar após a graduação, e, uma vez no mercado laboral, consigam encarar um país que requer ser pensado e investigado, sobretudo, compreender a multiplicidade de discursos que convergem entre si.

O facto de todos os especialistas consultados, mediante fontes primárias e secundárias, concordarem com a reduzida dimensão do mercado português na procura de crowdfunding, sugere que o seu desenvolvimento só será possível por meio da internacionalização, isto é, da seleção de temáticas do jornalismo de investigação de procura transnacional, bem como por um adequado planeamento, divulgação e marketing, associado sempre a conhecimentos de ciências empresariais e de economia.

\section{Considerações finais}

A economia particular do crowdfunding sugere que este pode ser, em Portugal como noutros países, uma alternativa aos modelos tradicionais de financiamento para empreendedores ou empresas que pretendem levar a cabo um determinado projeto, seja ele um produto, seja um serviço. No caso particular do jornalismo, diversas plataformas bem-sucedidas têm-se revelado uma alternativa para muitos profissionais com as competências necessárias para realizar trabalhos de investigação e que recebem com o apoio de financiadores dispostos a pagar por reportagens que não têm lugar nos media 
tradicionais. Esse modelo tem dado origem a novas formas de exercício da profissão, em que o jornalista conta com a colaboração dos utilizadores, tanto no que respeita à proposta de temas de investigação como no que se refere ao acompanhamento no terreno e às sugestões que podem ir sendo dadas ao longo do trabalho. Os financiadores tornam-se também contribuidores não só de fundos, como também de ideias, de uma forma que acaba por juntar o elemento do crowdsourcing, revelando uma inteligência coletiva a favor do jornalismo.

Tudo indicava que os projetos de crowdfunding em jornalismo tinham todos os fatores necessários para serem bem-sucedidos em Portugal, devido às dificuldades e às restrições gerais e particulares com que os media nacionais e os jornalistas se debatem atualmente. No entanto, a situação real demostra um impacto praticamente nulo do crowdfunding como forma de sucesso e financiamento do jornalismo de investigação nesse país. A única plataforma nacional dedicada exclusivamente a acolher projetos jornalísticos de investigação contou apenas com um projeto de jornalismo de investigação executado, o que se deveu não à fraca procura dos leitores, mas, principalmente, à falta de capacidade empreendedora dos jornalistas. A análise dos planos curriculares de todos os cursos em todos os graus académicos em Portugal permitiu confirmar que, excetuando um doutoramento em CC na ULP, não existe uma objetiva abordagem do empreendedorismo nem de economia nesses cursos e graus no país.

Assim, sugere-se uma maior e melhor coordenação desses cursos no seio de outros existentes nas IES, nomeadamente, com as Faculdades de Economia e Gestão, para que exista uma mais consistente integração ao nível curricular que permita o desenvolvimento integral de competências no Ensino Superior em Portugal. Recomenda-se a inserção de UCs de Economia em geral e de Gestão/Empreendedorismo em particular, de forma a capacitar os futuros profissionais e investigadores da área de CC e a permitirlhes o desenvolvimento profissional adequado à situação atual.

Uma futura e mais aprofundada análise deverá ainda investigar outras razões do insucesso da plataforma I Fund News, compreender que ca- 
minhos têm seguido os jornalistas experientes sem emprego para tentarem levar a bom porto os desígnios da sua profissão, bem como compreender a postura dos financiadores portugueses perante a possibilidade de contribuírem para projetos de investigação jornalística propostos pelos jornalistas ou à sua medida.

\section{Referências}

A3ES - Agência de Avaliação e Acreditação do Ensino Superior em Portugal (2015). Avaliação de Cursos em funcionamento. Recuperado em 10 out. 2015 de http://www.a3es.pt/

Agrawal, A., Catalini, C. e Goldfarb, A. (2011). The geography of crowdfunding. NBER Working Paper, 16820. Recuperado em 10 maio 2015 de http://www.nber.org/papers/w16820

Agrawal, A., Catalini, C. e Goldfarb, A. (2013). Some simple economics of crowdfunding. NBER Working Paper, 19133. Recuperado em 10 fev. 2015 de http://www.nber.org/papers/w19133

Aitamurto, T. (2011). The impact of crowdfunding in journalism - Case study of Spot.us, a platform for community-funded reporting. Journalism Practice, 5(4), 23-35.

Barabas, R. L. (2012). Crowdfunding: Trends and developments impacting entertainment entrepreneurs. Recuperado em 10 jan. 2015 dehttp://www.disantolaw.com/wp-content/uploads/2012/10/ EASLJSummer1211.pdf

Belleflamme, P., Lambert, T. e Schwienbacher, A. (2010). Crowdfunding: An industrial organization perspective. Em Workshop Digital Business Models: Understanding Strategies, Paris, 7-9 jun. 2010. Proceedings from Workshop Digital Business Models: Understanding Strategies, Paris, 7-9 Jun 2010 (pp. 25-26). 
Belleflamme, P., Lambert, T. e Schwienbacher, A. (2014) Crowdfunding: Tapping the right crowd. Journal of Business Venturing, 29(5), 585609. Recuperado em 16 abril 2016 de http://www.sciencedirect. com/science/journal/08839026/29/5

Becker, V., Gambaro, D. e Souza Filho, G. L. (2015). O impacto das mídias digitais na televisão brasileira: queda da audiência e aumento do faturamento. Palabra Clave, 18(2), 341-373. Doi: 10.5294/pacla.2015.18.2.3

Bogost, I. (2012). Kickstarter: Crowdfunding platform or reality show? Fast Company. Recuperado em 21 jan. 2015 de http://www.fastcompany.com/1843007/kickstarter-crowdfunding-platform-orreality-show

Carvajal, M., Garcia-Avilés, J. A. e González, J. L. (2012). Crowdfunding and non-profit media, Journalism Practice, Special Issue: The Future of Journalism 2011. Developments and Debates, 6(spe), 5-16. Recuperado em 22 fev. 2015 de http://www.tandfonline.com/ doi/abs/10.1080/17512786.2012.667267

De Buysere, K., Gajda, O., Klevelan, R. e Marom, D. (2012). A Framework for European Crowdfunding. Mediascope Europe, Recuperado em 15 fev. 2015 de https://d21buns5ku92am.cloudfront. net/26522/documents/17930-1351284179-FRAMEWORK EU_CROWDFUNDING.pdf

Carvalhão, J. (2015). A plataforma I Fund News e seu integral funcionamento. Comunicação pessoal. Não publicada.

Gerber, E. M., Hui, J. S. e Kuo, P. Y. (2012). Crowdfunding: Why people are motivated to post and fund projects on crowdfunding platforms. Working paper Northwestern University Creative Action Lab. Recuperado em 10 mar. 2015 de http://distworkshop.files. wordpress.com/2012/01/dist2012_submission_11.pdf 
Howe, J. (2007). Breaking the news: Faced with fewer ads and a dwindling audience, the country's biggest newspaper chain set out to reinvent the business. Wired Review, 15(8), 86.

Howe, J. (2008). Crowdsourcing. why the power of the crowd is driving future of business. Nova York: Three Rivers Press.

Kleemann, F., Vob, G. e Rieder, K. (2008). Un(der)paid Innovators: The commercial utilization of consumer work through crowdsourcing. Science, Technology \& Innovation Studies, 4(1), 5-26. Recuperado em 16 abril de 2016 http://www.sti-studies.de/ojs/index.php/sti/ article/view/81

Lawton K. e Marom, D. (2011). The crowdfunding revolution: Social networking meets venture financing. Recuperado em 10 fev. 2015 de http: / / aims.stanford.edu/images/speakers/2-9-11_lawton/020911\%20 AIMS\%20lawton\%20flier.pdf

Mollick, E. (2014). The dynamics of crowdfunding: Determinants of Success and Failure. An Exploratory Study. Journal of Business Venturing, 29(1), 1-16.

Ramos, J., González, B., Llorca, R., Mayor, L. e Porcel, R. (2013). Micro financiación colectiva (crowd-funding): un nuevo instrumento económico para el crecimiento económico y el empleo. Un análisis de los efectos económicos de la micro-financiación colectiva con especial énfasis en el caso español. Fundación Catalunya Europa, Barcelona. Recuperado em 10 mar. 2015 de http: / /www.catalunyaeuropa.net/img/pdf/Paper_CF_Ateneu.pdf

Rivera, B. E. (2012). Crowdfunding: la eclosión de la financiación colectiva, un cambio tecnológico, social y económico. Barcelona: Microtemas.

Roncallo-Dow, S., Uribe-Jongbloed, E. e Calderón-Reyes, I. (2013). La investigación en comunicación: los límites y limitantes del conocimiento. Co-herencia, 10(18), 161-187. Recuperado em 20 out. 2015 
dehttp://webcache.googleusercontent.com/search?q=cache:qh2r hfQheZMJ:publicaciones.eafit.edu.co/index.php/co-herencia/article $/$ download $/ 2137 / 2094+\& c d=1 \&$ hl $=$ pt-PT $\& \mathrm{ct}=\mathrm{clnk} \& \mathrm{gl}=\mathrm{pt}$

Schwienbacher, A. e Larralde, B. (2012). Crowdfunding of small entrepreneurial ventures. Em D. J. Cumming (Ed.), The Oxford Handbook of Entrepreneurial Finance (pp. 8-13). Oxford: University Press.

Steinberg, S., De Maria, R. e Migicovsky, E. (2012). The crowdfunding bible: How to raise money for any startup, video game or project, J. Kimmich, Editions. Recuperado em 16 abril 2016 de http://www. crowdfundingguides.com/The\%20Crowdfunding\%20Bible.pdf 